\title{
User requirements for the snow and land ice services - CryoLand
}

\author{
E. Malnes ${ }^{1}$, A. Buanes ${ }^{1}$, T. Nagler ${ }^{2}$, G. Bippus ${ }^{2}$, D. Gustafsson ${ }^{3}$, C. Schiller ${ }^{4}$, S. Metsämäki ${ }^{5}$, J. Pulliainen ${ }^{6}$,

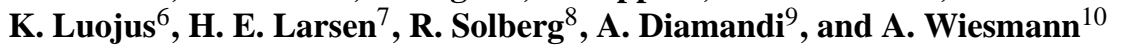 \\ ${ }^{1}$ Norut, Tromsø, Norway \\ ${ }^{2}$ ENVEO, Innsbruck, Austria \\ ${ }^{3}$ Swedish Meteorological and Hydrological Institute, Norrkjöping, Sweden \\ ${ }^{4}$ EOX, Vienna, Austria \\ ${ }^{5}$ Finish Environmental Institute, Helsinki, Finland \\ ${ }^{6}$ Finish Meteorological Institute, Helsinki, Finland \\ ${ }^{7}$ Kongsberg Satellite Services, Troms $\emptyset$, Norway \\ ${ }^{8}$ Norwegian Computing Centre, Oslo, Norway \\ ${ }^{9}$ Administratia Nationala de Meteorologie, Bucharest, Romania \\ ${ }^{10}$ Gamma Remote Sensing, Bern, Switzerland \\ Correspondence to: E. Malnes (eirik@ norut.no)
}

Received: 14 January 2015 - Published in The Cryosphere Discuss.: 6 February 2015

Revised: 30 April 2015 - Accepted: 11 May 2015 - Published: 5 June 2015

\begin{abstract}
CryoLand (2011-2015) is a project carried out within the 7th Framework of the European Commission aimed at developing downstream services for monitoring seasonal snow, glaciers and lake/river ice primarily based on satellite remote sensing. The services target private and public users from a wide variety of application areas, and aim to develop sustainable services after the project is completed. The project has performed a thorough user requirement survey in order to derive targeted requirements for the service and provide recommendations for the design and priorities of the service. In this paper we describe the methods used, the major findings in this user survey, and how we used the results to design and specify the CryoLand snow and land ice service.

The user requirement analysis shows that a European operational snow and land ice service is required and that there exists developed cryosphere products that can meet the specific needs. The majority of the users were mainly interested not only in the snow services, but also the lake/river ice products and the glacier products were desired.
\end{abstract}

\section{Introduction}

Several international organizations and projects devoted to remote sensing of the cryosphere have reviewed the requirements from their users for future products and services targeting different application fields (GCOS-107, 2006; Malenovský et al., 2012). This paper reviews recent requirements for snow, lake/river ice and glacier products and services in addition to documenting our own user survey. Finally, it presents consolidated user requirements which were used throughout the CryoLand project to design optimal products and services serving a field of applications.

CryoLand is an EU funded research project aimed at developing, implementing and validating a standardized and sustainable service on snow and land ice monitoring as a downstream service within Copernicus (The European Earth observation programme) in a value added chain with the Copernicus Land Monitoring Services. The CryoLand project team consists of private and public research institutes, small- and medium-sized companies and satellite image providers. According to the project plan (http://www. cryoland.eu), the service will provide geospatial products on the seasonal snow cover (snow extent, snow mass, melt state), glaciers (area, snow/ice extent, ice velocities, glacier dammed lakes) and lake/river ice (extent, temporal varia- 
Table 1. List of projects/organizations that have performed user surveys and/or made recommendations for snow, glacier, lake/river ice products and web-map services lately.

\begin{tabular}{llcccc}
\hline Name & Funding & Snow & Glacier & $\begin{array}{c}\text { Lake/river } \\
\text { ice }\end{array}$ & Infrastructure \\
\hline GCOS & UN & X & X & X & \\
IGOS & UN & X & X & X & \\
EnviSnow & EU FP5 & X & & & \\
GlobSnow & ESA & X & & & \\
GlobGlaciers & ESA & & X & & \\
CCI Glaciers & ESA & & X & & \\
CryoClim & ESA & X & X & & \\
DUE Permafrost & ESA & X & & $X$ & \\
NAM & Romania & X & & X & \\
GLOF & ESA & & X & & \\
GLIMS & NASA & & $X$ & & \\
Polarview & ESA & X & X & X & \\
STSE North Hydrology & ESA & & & $X$ & X \\
OGC & & & & & X \\
INSPIRE & EU & & & & \\
\hline
\end{tabular}

tions, snow burden) derived from Earth observation satellite data in response to user needs. Operational processing lines and service infrastructure for various product types will be developed on top of existing web service environments (decentralized business process architectures) supporting the publication, provision and chaining of geospatial data services. User information services offering interactive map search and order functions via Web browsers will be designed in a corporate "CryoLand Geoportal". Full end-to-end system tests and verification in pre-operational environment has been performed in cooperation with users in near real time. Finally, the transition of the services developed within the project to an operational self-supportive snow and ice monitoring service is planned.

The objective of the user survey was to ask potential customers about their expectations and needs for a snow and land ice service. Their answers and additional requirements derived from user surveys in previous projects and reports from major stakeholders within hydrology and cryosphere research is subsequently analysed in order to derive the consolidated user requirement in CryoLand which has been used throughout the project as a steering instrument in the service development.

\section{Methods}

CryoLand used multiple approaches to obtain as much information as possible from the users before the products and services were developed and specified. This ensures that the service was in line with user needs and expectations. The methods applied were to review requirements from previous cryosphere monitoring projects, to perform web-based user surveys and to discuss products and services with users di-

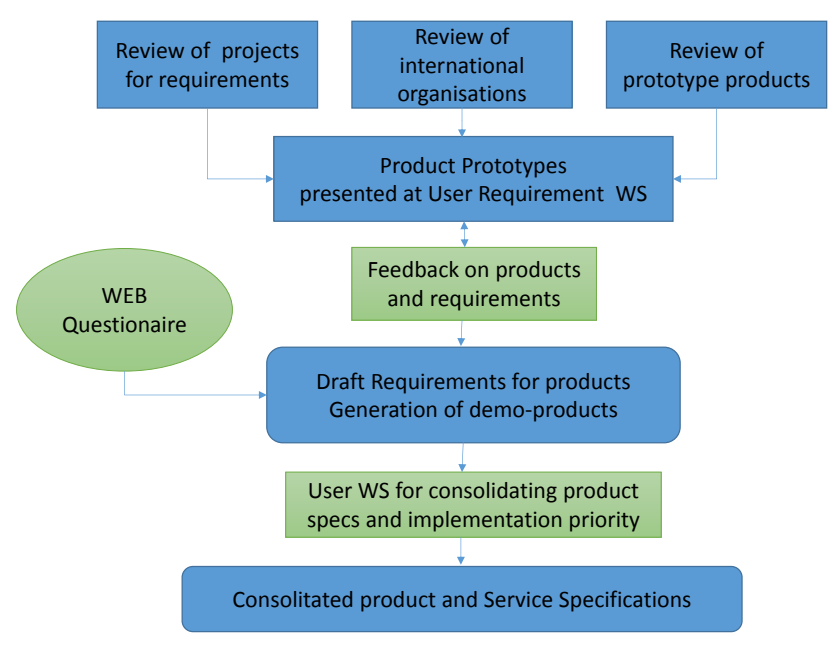

Figure 1. Methods applied to derive user requirements.

rectly in user workshops. The wide aspects of collected requirements finally enable us to define services and products for a wider European market. Figure 1 gives an overview of the methods applied to derive the user requirements.

\subsection{Review of published requirements on snow and land ice products}

Before the initiation of the user survey, the project performed a thorough review of previous user surveys and user recommendations for snow, glacier and lake/rivers ice products and web map services as specified by international working groups and organizations as well as from projects carried out since 2000. The analysed projects, their funding, and type of products they cover are listed in Table 1. 
The implementation plan for the Global Observing System for Climate in support of the UNFCCC (United Nations Framework Convention on Climate Change) (GCOS107, 2006) serves as the basic document on observations of climate variables including parameters from the seasonal snow pack, glaciers and lake/river ice. It is compiled under the guidance of the GCOS Steering Committee, with feedback from several hundreds of international experts.

Recommendations and requirements for cryospheric observations were published in the IGOS Cryosphere Theme report (IGOS, 2007). It emphasizes the need for sharing cryospheric observations and data products due to the high costs and importance of satellite instruments for the delivery of consistent observations of the global cryosphere. The primary snow product is a continuous data record of snow extent on a global scale. Wet snow should also be monitored consistently with current sensors, while snow depth and snow water equivalent (SWE) are highly desirable, and require investments in sensors and research to become observable at a suitable scale/accuracy. Lake/river ice is not directly mentioned in the list of essential climate variables (ECV), it is relevant through lake temperature which is linked to the lake freeze-up and break-up dates, serving as an indicator for regional climate modelling purposes.

\subsubsection{Snow}

The EU project EnviSnow (2002-2005) developed multisensor algorithms for retrieving snow information from Earth observation data. The EnviSnow user requirement assessment (EnviSnow, 2005) documented after a questionnaire that the main users requested regularly available accurate information on SWE and snow cover fraction (SCF). Some users request snow mass and/or snow cover extent (SE), which we in this paper regard as parallel products with similar information content. The main application area is improved runoff forecast by assimilation of snow products into hydrological models. Specific recommendations were given on thematic accuracy and spatial and temporal resolution for SWE and SCF products in particular.

The ESA project GlobSnow (2008-2014; http://www. globsnow.info) derived its user requirements from a review meeting where representatives from several international agencies were present. GlobSnow partners concluded that snow monitoring products shall represent harmonized and globally consistent observations of the snow cover independent of sensor, landscape or algorithm. All provided products were requested to be validated against in situ data and quality controlled. Based on the requirements from the users, the GlobSnow consortium developed a daily, weekly and monthly SWE product starting from 1978 and for the snow extent from 1995.

\subsubsection{Glaciers}

The ESA ECV Glaciers and Icecaps addresses three products, namely: glacier outlines (area), glacier surface elevation change and glacier surface velocity. All products shall meet the quality recommendations defined in the IGOS Cryosphere Theme report (IGOS, 2007).

A main international initiative for worldwide observation of glaciers is the Global Land Ice Measurement from Space (GLIMS) project (Bishop et al., 2004; Raup et al., 2007). GLIMS is a cooperative effort of over 60 institutions worldwide with the goal of inventorying a majority of the world's estimated more than 198000 glaciers. The GLIMS glacier database is accessible at http://glims.org. GLIMS lists basic glacier parameters such as glacier outlines, centre lines, snow lines, etc., to be derived from the satellite data, but does not define a quantitative list of requirements.

\subsubsection{Lake and river ice}

The ESA project Support To Science Element (STSE) North Hydrology (2010-2013) has documented user requirements related to lake/river ice observations (Fernández-Prieto et al., 2012). The document contains the scientific and operational requirements associated with the major themes of the North Hydrology project. The users include the CliC scientific community, the numerical weather prediction (NWP) and regional climate modelling (RCM) community, the hydrology community, and national and regional operational authorities. The main findings in the North Hydrology project are that the user groups wish to acquire satellite products from surface temperature and ice cover (fractional coverage) to be used in assimilation in climate models. Also within hydrological modelling, the project identified a growing interest in river and lake ice products.

\subsubsection{Infrastructure}

After reviewing the spatial data infrastructure and service needs of various initiatives and projects, it has been found that Open Geospatial Consortium (OGC) web services are being used for service provisioning and data access. Due to the complexity of environmental algorithm developments, data fusion and information provisioning, it seems that distributed web services, installed at the location of best expertise in combination with organizations which get funded to provide sustainable services, could provide the high quality and reliability of the information needed.

The EU INSPIRE (Infrastructure for Spatial Information in the European Community) directive encourages the sharing of spatial data free of charge. INSPIRE intends to trigger the creation of a European spatial information infrastructure that delivers integrated spatial information services to the users. These services should allow the users to identify and access spatial or geographical information from a wide 
range of sources, from the local level to the global level, in an interoperable way for a variety of uses. Most of the documents reviewed have adopted the idea of free data policy. Most of the products should be free of charge for all relevant users. However, tailored products for customers such as an industry would be chargeable in order to allow sustainable services to operate.

\subsection{Identification of potential users}

Parallel to the review of user requirements from previous projects, the CryoLand project partners identified potential users and user segments that should be approached for the user survey. An exhaustive list of institutions and contact persons was developed and maintained in a spreadsheet. The list contained users from the following user segments: hydrology, hydropower, climate research, environment conservation, avalanche monitoring and road maintenance. CryoLand contacted users in most European countries, but, as expected, the main response and interest was obtained from countries where snow and land ice play a major role, such as Nordic and Alpine countries.

\subsection{User workshops}

In May/June 2011 four user workshops were held in Vienna, Oslo, Helsinki and Bucharest to address users from mid,southern and northern Europe. At the user workshops the status of the product and service portfolio available at the CryoLand partners were presented, and the users discussed and commented on all parts of the products and services. After the first year of the project a new user conference was held in Stockholm in May 2012 to discuss and consolidate the proposed products and services. The user inputs from the workshops were properly documented in minutes and also played an important part in the final user requirements and specification of the products and services.

\subsection{User survey}

A questionnaire was designed based on the review from previous projects. The partners in CryoLand refined the questionnaire several times to ensure that the questions covered all aspects of the project. The questionnaire was organized in six sections:

1. general information on the user, including contact person, address, etc.;

2. present status of using snow and ice information in the organization;

3. specific requirements for snow products;

4. specific requirements for glacier products;

5. specific requirements for lake/river ice products;
Table 2. Type of organizations.

\begin{tabular}{lrr}
\hline & \multicolumn{2}{c}{ Total } \\
\cline { 2 - 3 } Type of organization & Percentage & Number \\
\hline Private company & $16 \%$ & 19 \\
National authority* & $25 \%$ & 30 \\
Regional authority* & $15 \%$ & 18 \\
Scientific* & $19 \%$ & 23 \\
Consulting & $11 \%$ & 13 \\
Other & $13 \%$ & 16 \\
\hline Total & $100 \%$ & 119 \\
\hline * Several respondents identified their organization in more than \\
$\begin{array}{l}\text { one category, e.g. a meteorological office can have national and } \\
\text { regional authority and perform scientific work. }\end{array}$
\end{tabular}

6. technical information on service interfaces and services itself.

The questionnaire closes with the question if users are joining the CryoLand user group.

The questionnaire was implemented as a web questionnaire in the software tool Enalyzer (http://www.enalyzer. com). The questionnaire was launched on 6 June 2011 for the Alpine users and on 9 June 2011 for Nordic users, synchronized with user workshops in the respective areas. A total of 47 users from 37 organizations completed the questionnaire.

\section{Results}

The results from the user survey were organized in different sections according to thematic products and technical questions related to the service.

\subsection{General questions - user characteristics}

A total of 47 users completed the questionnaire. The majority of responding users are from Austria, Norway and Sweden, but the Czech Rep., Denmark, Finland, Germany, Romania, Italy and Switzerland were also represented among the users. Figure 2 shows a histogram representation of the users that responded to the survey, and the geographical distribution of the users.

A diversity of organization types were represented (Table 2), but the largest organization type was national authorities $(25 \%)$. It should be noted that some of the users selected more than one type of organization (e.g. national and scientific). Although a clear majority of the users represent the public sector (national, regional, scientific), there is also a significant amount of interest among several of the other organization types.

The users were also asked to estimate the number of employees in their organization. The number ranged from 1 to 5000 employees with a mean number of employees around 400 and a median number around 200. This indicates 

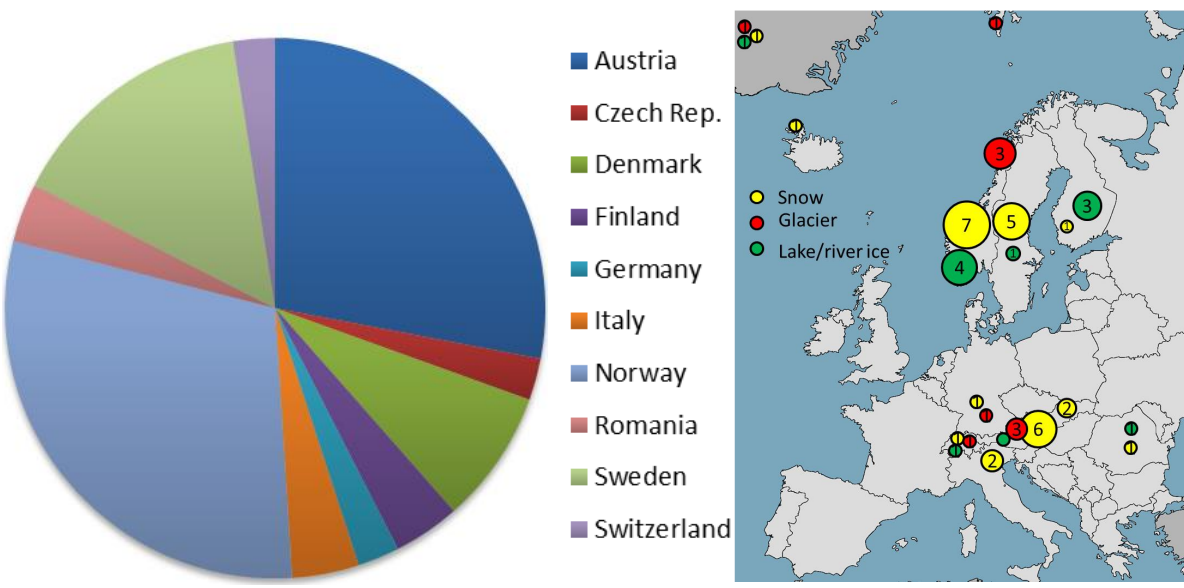

Figure 2. Nationalities of the users that responded to the user survey (left panels). Right panels: location of the users and their field of interest. Dots are scaled according to the number of respondents.

that the bulk of the user organizations are rather large and typical public organizations.

The respondents also indicated their main application area. Avalanche and road management, hydrology and flood forecast, glaciology, weather forecast, vegetation research and climate research. Figure 3 shows the how the application areas are distributed among the respondents. Depending on their application area, the users provided a wide variety of desired product types or services in an open section of the questionnaire. There was a geographical bias in some of the application areas (e.g. glaciology and lake/river ice), but few respondents in each country yielded inconclusive findings with respect to the geographical distribution of the application areas. In the general section of the user survey, the users were also asked to indicate which of the three product categories (snow, lake/river ice and glacier) they were interested in. $84 \%$ responded that snow products were important, around $24 \%$ regarded lake ice and $24 \%$ glacier products as important.

\subsection{User requirements for snow service}

A total of $91 \%$ of the respondents were interested in snow products. Most users $(84 \%)$ regarded the snow fraction products as important, the low resolution SWE product was ranked high by $55 \%$, whereas the other had ratings between 34 and $46 \%$ ranked in descending order: melting snow, statistical snow extent, surface wetness, albedo maps and snow surface temperature (Fig. 4).

Most users need snow products as a full year service, but regard autumn/winter/spring as more important than summer. The autumn season is ranked almost as important as spring for several products. The majority of respondents indicated that all products should be provided on a daily basis. A majority need a latency time shorter than $12 \mathrm{~h}, 31 \%$ shorter than $6 \mathrm{~h}$. Most users can use products with $250 \mathrm{~m}$ resolution.

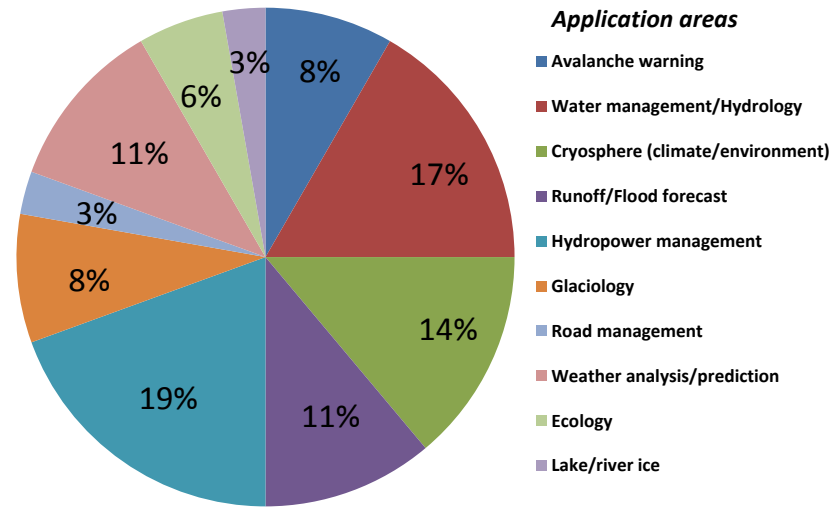

Figure 3. Application fields of users.

Some users, like avalanche and road authorities need high resolution data down to at least $50 \mathrm{~m}$ resolution, but such a requirement cannot be met with the sensors currently available on a daily basis, at least not within a reasonable cost frame.

The majority of the users desire regional products over the Alps including Romania and in the Nordic countries. Many users $(83 \%)$ also ask for Pan-European products. The majority of respondents $(53 \%)$ preferred UTM projections. The remainder preferred geographic coordinates $(38 \%)$ or other projections $(10 \%)$, like the Lambert azimuth equal-area for Europe.

\subsection{Requirements for the glacier service}

When asked about glacier products, $36 \%$ of the respondents said that they were interested in glacier products. Out of this, $88 \%$ stated that the glacier outline product is the most relevant, while the other products had lower ratings (see Fig. 5). The summer is regarded as the most important period for ac- 
How relevant are the following CryoLand snow products?

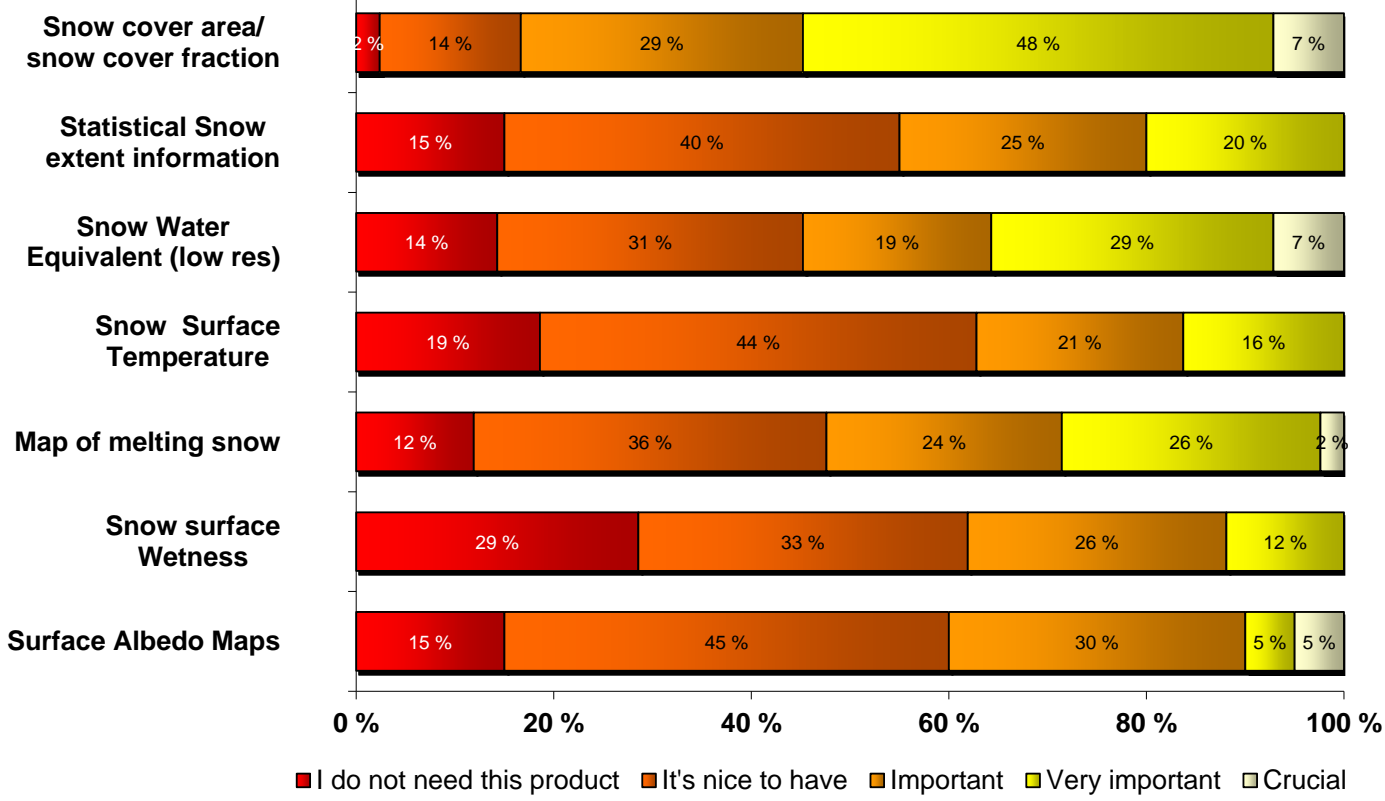

Figure 4. Relevance of snow products.

\section{How relevant are the following GLACIER products according to your needs?}

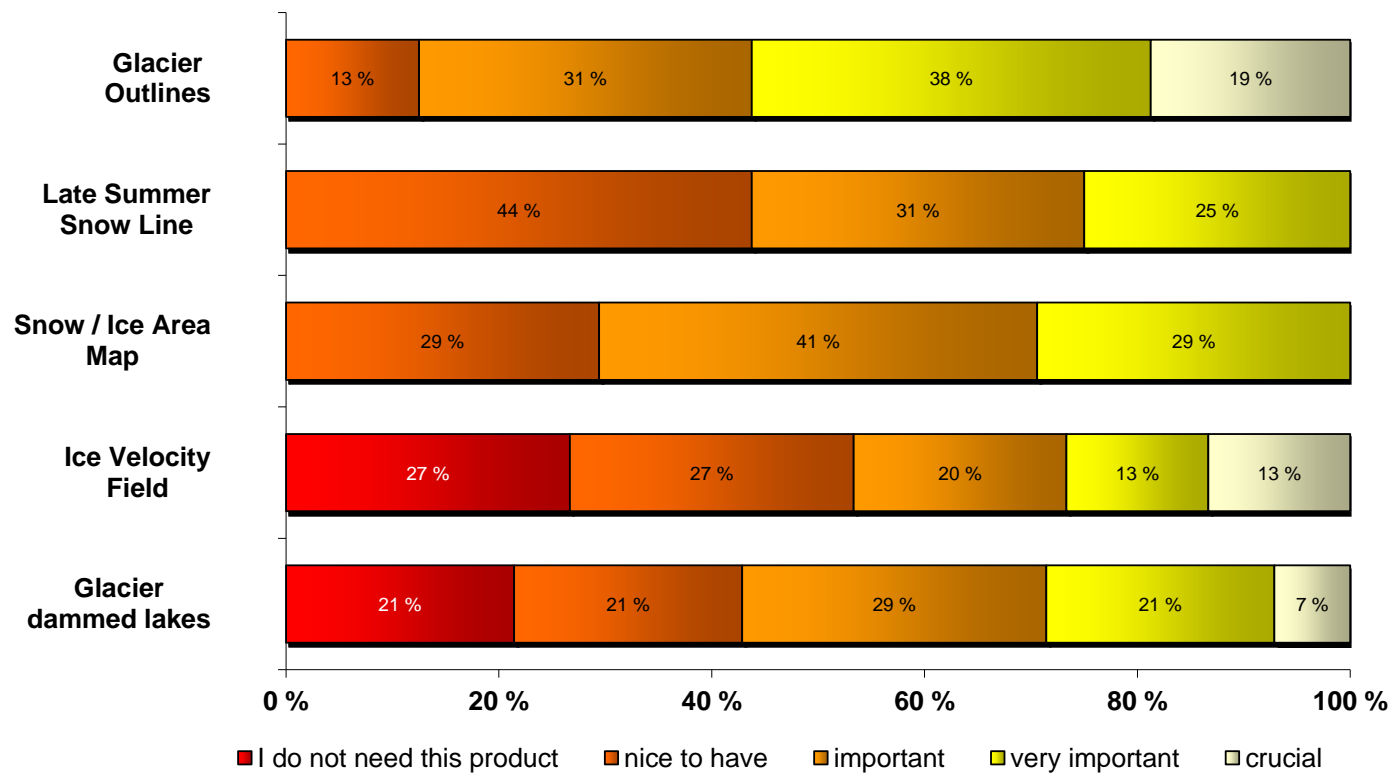

Figure 5. Relevance of glacier products.

quisitions of glacier products (by $90 \%$ ), and annual updates of the products were preferred by a majority of the users. The users need the product within 3 months.

All glacier products are desired at relatively high spatial resolution $(10-25 \mathrm{~m})$ by a majority of the respondents. A majority of the users (63-91\%, depending on product type) pre- ferred products in a UTM projection. A majority of the users were interested in glacier products from the Alps and Scandinavia including Svalbard and Greenland. 
How relevant are the following LAKE ICE products according to your needs?

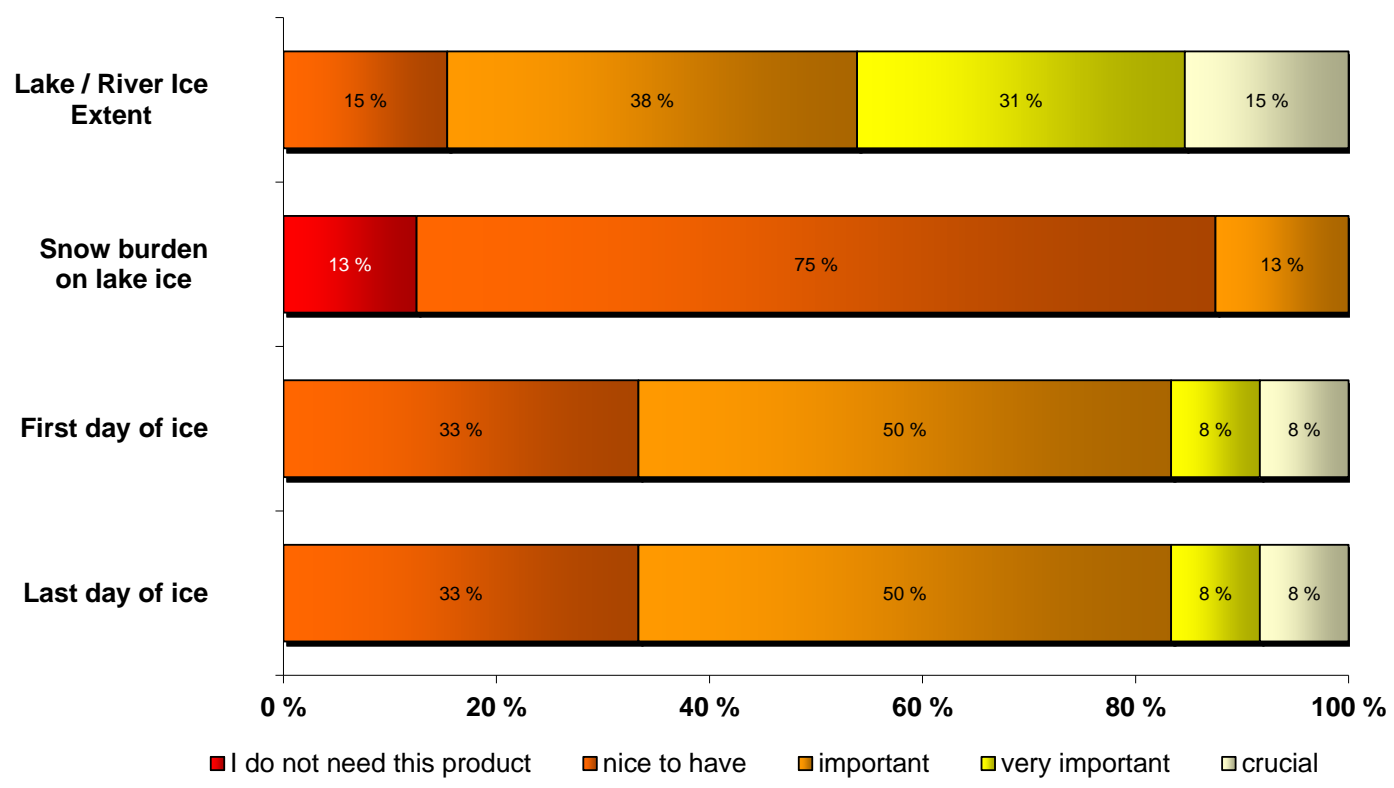

Figure 6. Relevance of lake ice products.

\subsection{Requirements for the lake and river ice service}

A total of $28 \%$ of the survey respondents are interested in lake ice products. Out of this $28 \%$, a large majority $(84 \%)$ regarded the lake and river ice extent product as important: first and last day of ice were rated high by $66 \%$ and snow burden was regarded important by $13 \%$ of these users (see Fig. 6).

A majority of the users require a temporal resolution of less than 2-3 days. The required latency time is dependent on product types. A few products like river ice jam and flood products are required in near real time, while other products are related to climate research, and requires annual updates. $33 \%$ of the users are interested in data with high resolution ( $25 \mathrm{~m}$, typically river ice products), $33 \%$ needed data with medium resolution $(100 \mathrm{~m})$ and the remainder needed data with less than $1 \mathrm{~km}$ resolution.

The preferred map projection for lake ice products as specified by the users is geographical coordinates (latitude, longitude). Users in Scandinavia show very high interest in lake and river ice products, while it is less requested for users in central Europe.

\subsection{Technical requirements for the CryoLand user service}

An important section in the user survey was related to the development of the CryoLand user service. The users were asked about specific issues related to the implementation of the service.

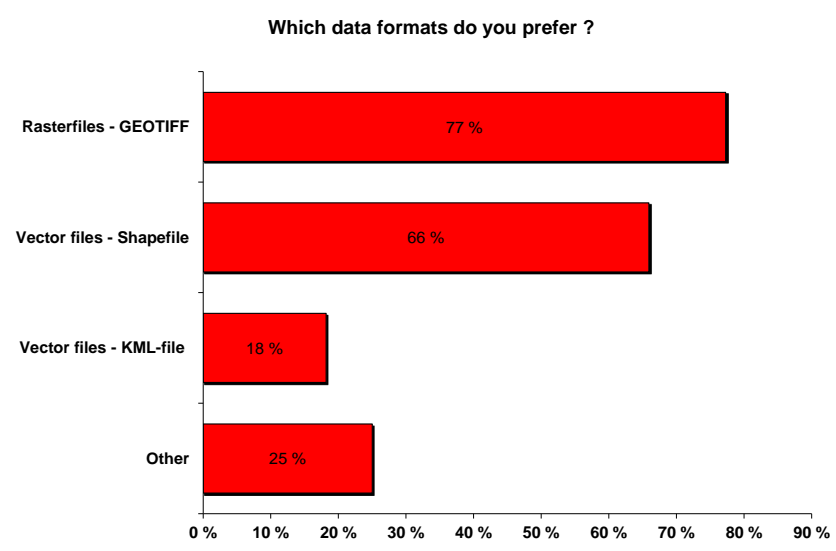

Figure 7. Preferred data formats.

When asked about data formats (see Fig. 7), the preferred raster format among the users is geotif $(77 \%)$, whereas shape is the preferred vector format $(66 \%)$. A total of $94 \%$ of the users prefer to access CryoLand products in a Web-GUI; $76 \%$ preferred to view products in a Web-GUI, $61 \%$ also wanted to view CryoLand products in an OpenGIS map service. The most favoured downloading method is FTP $(73 \%)$. Using OpenGIS web feature service (WFS) is also of high interest $(46 \%)$. A total of $62 \%$ wanted to use the CryoLand Web-GUI to invoke processing services offered by CryoLand; $50 \%$ preferred upload of reference data using WFS-T as a necessary option for data upload; $46 \%$ liked the idea of uploading files utilizing the CryoLand Web-GUI. 
ESRI ARC GIS is the dominating software system in use, with OpenSource tools being the second largest group.

The preferences in this section were expected since many of the users are scientists and are used to the ARC GIS market standard. Open GIS is still not widely used for analysis among these users.

\section{Discussion}

Based on the reviews on previous projects, the discussions with the users at workshops and finally the thorough user survey, we are confident to conclude that the prioritization of products and services reflects the needs of a wide user community interested in snow and land ice services within Europe. A large number of users within all the user segments that CryoLand addresses have responded. The responses gave, in most cases, clear directions towards which products and services that should be implemented.

As a critical point one might argue that the geographical spread of the users is somewhat biased as most of the users are located within the Nordic and the Alpine countries in Europe. Though this is quite natural since these are the countries where snow plays a major role, it is somewhat unsatisfactory that major countries like France, UK, Poland and Russia were poorly represented. The countries represented in CryoLand are dominating the user community.

\section{Balancing requirements against what is achievable with current technology}

Since the questionnaire was open regarding which services are possible to implement with current and near future satellite sensors, there is a need to harmonize the user requirements (as they appear from the statistical results of the questionnaire) with what is achievable during the lifetime of the CryoLand project. The analysis below takes into account the user requests on the one hand, and the available EO data and status of retrieval algorithms and processing lines for the different products of the CryoLand product portfolio on the other hand. Based on discussions in the user workshops, it was proposed to group the baseline CryoLand products into three categories depending on their level of maturity. The product categories are

- category 1: operational products (a few very important products/data sets);

- category 2: pilot products (emerging operational products; undergoing full validation);

- category 3: experimental products (delivered on demand; limited validation).

Most resources in the CryoLand project should go into research and development in Category 1 . It is the intention that
CryoLand should be able to increase the portfolio of Category 1 products by fulfilling work on validation for Category 2 products. Experimental products are important and they may also be important products in the future. CryoLand, with its Copernicus downstream focus, is however not able to put significant resources into $\mathrm{R} \& \mathrm{D}$ for this category, but the project is an arena to discuss future products with the users and provide them with test samples.

Table 3 provides the consolidated product and service requirements. The spatial and temporal coverage were defined and consolidated by users operating in different applications. Due to the variety of products discussed it was necessary to specify the implementation priority of the products. Based on the ranking in the user survey, discussions within the CryoLand consortium and at the CryoLand user consultation meeting held in Stockholm in May 2012, we set an implementation priority for products and services within CryoLand. Different aspects were taken into account, including the size of the user community having interest in the product but also the availability of EO data and the matureness of the algorithms for generating the product.

Table 3 gives implementation priority for individual products. In order to simplify this, we order the ranking in categories 1, 2 and 3. Table 3 shows that the highest ranked snow products are the regional and the Pan-European snow extent products. Glacier extent and lake/river ice extent is also ranked high among their user communities.

\section{Conclusions}

The CryoLand project is aimed at developing, implementing and validating a standardized and sustainable service on snow and land ice monitoring as a downstream service within the Copernicus framework of the EU. The results from the CryoLand user requirement assessment clearly demonstrate that there is a need for a European operational service and well developed cryosphere products that can meet the specific needs. The majority of the users were mainly interested in the snow services, but also the lake/river ice products and the glacier products were desired. The user survey gave the project guidance and priorities for the further development of products and services.

The products were organized in three categories (operational products, pilot products and experimental products) based on the user ranking and the operational status of the products. This ordering gave the project directions to the implementation order and to the efforts needed to improve certain products.

The Copernicus sensors Sentinel-1, -2 and -3 will be well suited for addressing most of the prioritized products when they become operational from 2015. A particular point that was highlighted during the user requirement survey was the need for Pan-European services for snow water equivalent and snow cover fraction. These services, in addition to the 
Table 3. Requirements for spatial and temporal resolution of products and product ranking.

\begin{tabular}{|c|c|c|c|c|c|}
\hline $\begin{array}{l}\text { Product } \\
\text { type }\end{array}$ & $\begin{array}{l}\text { Spatial } \\
\text { resolution }\end{array}$ & $\begin{array}{l}\text { EO } \\
\text { sensors }\end{array}$ & $\begin{array}{l}\text { Temporal } \\
\text { resolution }\end{array}$ & $\begin{array}{l}\text { Implementation } \\
\text { priority }\end{array}$ & $\begin{array}{l}\text { User } \\
\text { ranking } \\
{[\%]}\end{array}$ \\
\hline $\begin{array}{l}\text { Snow cover } \\
\text { fraction, regional in } \\
\text { Nordic and Alps }\end{array}$ & $250-500 \mathrm{~m}$ & MODIS, ASAR (archived), S1, S3 & Daily, full year & 1 & $83 \%$ \\
\hline Snow extent (local) & $25-50 \mathrm{~m}$ & Landsat, S2 & Monthly, full year & NA & NA \\
\hline $\begin{array}{l}\text { Snow cover } \\
\text { fraction, pan-European }\end{array}$ & $500-1000 \mathrm{~m}$ & MODIS, S1,S3 & Daily, full year & 1 & $83 \%$ \\
\hline $\begin{array}{l}\text { Snow water equivalent } \\
\text { (Low res) }\end{array}$ & $10-25 \mathrm{~km}$ & SSMI/S, AMSR2 & $\begin{array}{l}\text { Daily, dry snow } \\
\text { season }\end{array}$ & 2 & $55 \%$ \\
\hline Melting snow area & $25-100 \mathrm{~m}$ & ASAR (archived), Sentinel S1, S3 & Daily & 2 & $52 \%$ \\
\hline Snow surface wetness & $1000 \mathrm{~m}$ & MODIS, Sentinel S3 & Daily & 3 & $38 \%$ \\
\hline $\begin{array}{l}\text { Statistical snow } \\
\text { information }\end{array}$ & HRU/basin & NA & Daily & 2 & $45 \%$ \\
\hline Spectral surface albedo & $250-500 \mathrm{~m}$ & MODIS, Sentinel S3 & Daily & 3 & $40 \%$ \\
\hline $\begin{array}{l}\text { Snow surface } \\
\text { temperature }\end{array}$ & $1000 \mathrm{~m}$ & $\begin{array}{l}\text { MODIS, } \\
\text { Sentinel S3 }\end{array}$ & Daily & 3 & $37 \%$ \\
\hline Glacier outlines & $10-25 \mathrm{~m}$ & $\begin{array}{l}\text { SPOT, Landsat, Ikonos, } \\
\text { Sentinel S2 }\end{array}$ & Annually & 1 & $88 \%$ \\
\hline $\begin{array}{l}\text { Snow/ice area } \\
\text { on glaciers }\end{array}$ & $<25 \mathrm{~m}$ & $\begin{array}{l}\text { ASAR (archived), TSX, } \\
\text { Landsat TM, SPOT, } \\
\text { Sentinel S2 }\end{array}$ & Annually & 2 & $71 \%$ \\
\hline Glacier ice velocity & $10-25 \mathrm{~m}$ & $\begin{array}{l}\text { TSX, } \\
\text { Sentinel }\end{array}$ & Annually & 2 & $57 \%$ \\
\hline Glacier lakes & $10-25 \mathrm{~m}$ & $\begin{array}{l}\text { TSX, } \\
\text { Sentinel }\end{array}$ & $\begin{array}{l}\text { Annually, } \\
\text { weekly (fast analysis), } \\
\text { hours (emergency) }\end{array}$ & 2 & $57 \%$ \\
\hline $\begin{array}{l}\text { Ice extent and ice } \\
\text { concentration }\end{array}$ & $100 \mathrm{~m}$ & $\begin{array}{l}\text { MODIS, ASAR (archived), TSX, } \\
\text { Sentinel }\end{array}$ & Daily, Oct-May & 1 & $85 \%$ \\
\hline $\begin{array}{l}\text { Snow covered area on } \\
\text { lake ice }\end{array}$ & $250 \mathrm{~m}$ & $\begin{array}{l}\text { MODIS, } \\
\text { Sentinel S1 }\end{array}$ & Daily & 3 & $13 \%$ \\
\hline $\begin{array}{l}\text { Snow surface } \\
\text { temperature }\end{array}$ & $1000 \mathrm{~m}$ & MODIS, Sentinel S3 & Daily & 3 & $37 \%$ \\
\hline $\begin{array}{l}\text { First and last day } \\
\text { of ice cover }\end{array}$ & $100 \mathrm{~m}$ & $\begin{array}{l}\text { MODIS, ASAR (archived), } \\
\text { TSX, Sentinel }\end{array}$ & Annually & 2 & $67 \%$ \\
\hline $\begin{array}{l}\text { River ice jam, } \\
\text { flood inundation area }\end{array}$ & $30 \mathrm{~m}$ & ASAR (archived), TSX & Daily (emergency) & 3 & $\mathrm{n} / \mathrm{a}$ \\
\hline Lake surface temperature & $500 \mathrm{~m}$ & $\begin{array}{l}\text { MODIS, } \\
\text { Sentinel S3 }\end{array}$ & Daily & 3 & $\mathrm{n} / \mathrm{a}$ \\
\hline Snow depth on lake ice & $25 \mathrm{~km}$ & SSMI/S, AMSR2 & Daily & 3 & $\mathrm{n} / \mathrm{a}$ \\
\hline
\end{tabular}


need for highly accurate regional services, were prioritized the highest and, hence, were also rapidly implemented by the CryoLand consortium. A continuation of the CryoLandsnow and land ice services has been suggested as a Copernicus land monitoring core service. This service will need to focus on broadening the number of countries/users involved. 


\section{Appendix A: Abbreviations}

Table A1. Abbreviations used in the text. Mainly organizations and cryosphere-related acronyms.

\begin{tabular}{ll}
\hline CliC & Climate and Cryosphere, a WCRP core project \\
ECV & Essential climate variables \\
EO & Earth Observation \\
EU & European Union \\
FTP & File Transfer Protocol \\
GCOS & Global Climate Observing System \\
GIS & Geographic Information System \\
GLIMS & Global Land Ice Measurements from Space \\
GUI & Graphical User Interface \\
IGOS & Integrated Global Observing Strategy \\
NWP & Numerical Weather Prediction \\
OGC & Open Geospatial Consortium \\
RCM & Regional Climate Modelling \\
SCF & Snow Cover Fraction \\
SE & Snow Extent \\
SWE & Snow Water Equivalent \\
UK & United Kingdom \\
UNFCCC & United Nations Framework Convention on Climate Change \\
UTM & Universal Transverse Mercator \\
WFS & Web Feature Service \\
\hline
\end{tabular}


Acknowledgements. This work was financed by the European Union Copernicus project CryoLand (grant agreement \#262925). We acknowledge B. Raup, A. Devaris and an anonymous referee for valuable comments and suggestions for improvements.

Edited by: R. Brown

\section{References}

Bishop, M. P., Olsenholler, J. A., Shroder, J. F., Barry, R. G., Raup, B. H., Bush, A. B. G., Copland, L., Dwyer, J. L., Fountain, A. G., Haeberli, W., Kääb, A., Paul, F., Hall, D. K., Kargel, J. S., Molnia, B. F., Trabant, D. C., and Wessels, R.: Global Land Ice Measurements from Space (GLIMS): remote sensing and GIS investigations of the Earth's cryospher, Geocarto Int., 19, 57-84, 2004.

EnviSnow: User Requirement Draft Document, EnviSnow EVG1CT-2001-00052, http://www.learningace.com/doc/1091645/ f12286ef00e1fc974d6b9f88b3492da2/envisnow_requirements, last access: 4 June 2005.
Fernández-Prieto, D., Duguay, C., Gauthier, Y., Gustafsson, D., Malnes, E., Mattila, O.-P. , Rontu, L., Rott, H., Samuelsson, P., and Solberg, R.: ESA STSE North Hydrology: Development of multi-mission satellite data products in support of atmospheric and hydrological modeling of cold regions, Geophysical Research Abstracts, 14, EGU General Assembly, 22-27 April 2012, Vienna, Austria, 2012.

GCOS-107: Systematic Observation Requirements for SatelliteBased Products for Climate, WMO/TD-No. 1338, World Meteorological Organization, Geneva, Switzerland, 90 pp., 2006.

IGOS: Cryosphere Theme Report 2007, WMO/TD-No 1405, World Meteorological Organization, Geneva, Switzerland, 100 pp., 2007.

Malenovský, Z., Rott, H., Cihlar, J., Schaepman, M. E., GarcíaSantos, G., Fernandes, R., and Berger, M.: Sentinels for science: Potential of Sentinel-1, -2, and -3 missions for scientific observations of ocean, cryosphere, and land, Remote Sens. Environ., 15, 91-101, 2012.

Raup, B., Racoviteanu, A., Khalsa, S. J. S., Helm, C., Armstrong, R., and Arnaud, Y.: The GLIMS geospatial glacier database: A new tool for studying glacier change, Global Planet. Change, 56, 101-110, 2007. 